\title{
O USO DE METODOLOGIA ATIVA NO PROCESSO DE ENSINO/APRENDIZAGEM NAS AULAS DE GEOGRAFIA
}

\author{
Jaqueline Favarin Sasso favarin Dal Pont ${ }^{1}$ \\ Helio Aisenberg Ferenhof ${ }^{2}$
}

\section{RESUMO}

O educando da atualidade encontra-se desmotivado diante das metodologias tradicionais. $O$ que indica uma inconsistência da metodologia tradicional com a necessidade atual. Fato que faz indagar, será que o uso de Metodologia Ativa pode solucionar o problema da desmotivação dos discentes? Assim sendo, este trabalho tem como objetivo, relatar o uso de Metodologia Ativa, mais precisamente, de Aprendizagem Baseada em Problema (ABP), por meio de uma pesquisa-ação nas aulas de Geografia de um colégio estadual. Os resultados da pesquisaação apontam que a mesma contribuiu como suporte para a motivação do discente com o uso da Metodologia Ativa, em especial a ABP.

Palavras-chave: Metodologia Ativa, Ensino Aprendizagem.

\section{THE USE OF ACTIVE METHODOLOGY ON THE PROCESS OF LEARNING/TEACHING ON GEOGRAPHY CLASSES}

\begin{abstract}
The student of today is unmotivated by traditional methodologies. This fact indicates an inconsistency of the traditional methodology with the current need. A fact that makes you wonder, can the use of Active Methodology solve the problem of the demotivation of the students? Thus, this article aims to apply the use of Active Methodology, more precisely of Problem-Based Learning (PBL), through action research in the geography classes of a state college. The results of the action research point out that it contributed to support the motivation of the student with the use of the Active Methodology, especially the ABP. The current student is unmotivated by traditional methodologies, which indicates an inconsistency of the traditional methodology with the current need. A fact that makes you wonder, can the use of Active Methodology solve the problem of the demotivation of the students? Thus, this work aims to report the use of Active Methodology, more precisely, of Problem-Based Learning (PBL), through action research in the geography classes of a state college. The results of the action research point out that it contributed as a support for the student's motivation with the use of the Active Methodology, especially the PBL.
\end{abstract}

Keywords: Active Methodology, Learning Teaching.

\footnotetext{
${ }^{1}$ Graduada em Geografia, especialista em Metodologia do Ensino de História e Geografia- Secretariado Escolar - Gestão Escolar: Administração, Supervisão e Orientação. Professora efetiva da rede estadual e municipal do município de Morro Grande-SC. Email: jaquinhaf@yahoo.com.br

2 Professor Visitante do Programa de Pós-Graduação em Tecnologias da Informação e Comunicação da Universidade Federal de Santa Catarina. Email: helio.ferenhof@ufsc.br - Orcid:

https://orcid.org/0000-0001-5167-0838
} 


\section{INTRODUÇÃO}

O discente dos dias atuais da educação básica, estão exigindo novas posturas e estratégias pedagógicas, pois este pode ser considerado nativo digital, que se encontra inserido em rede e vive formas de aprender completamente diferente dos métodos tradicionais de ensino (MOREIRA; ANDRADE, 2018). Corroborando com esta ideia Prensky (2010), sustenta que o sistema educacional foi desenvolvido previamente, não atende aos discentes de hoje.

A pesquisa realizada por Moreira e Andrade (2018), aponta que utilizando o modelo tradicional de ensino, possivelmente, terá um discente desmotivado e desinteressado pela aula. Neste sentido, cabe ao docente começar a repensar suas metodologias, já que ensinar uma geração conectada e que vive em constante transformação, exige do docente atualização em suas práticas pedagógicas. Caso contrário, continuará um ensino baseado na transmissão de informação, na educação bancária que Paulo Freire (1970) criticou.

Com intuito de adequar-se ao discente nativo digital, este trabalho buscará suporte nas Metodologias Ativas, que de acordo com Blikstein (2010) e Prensky (2001) pode auxiliar no processo ensino-aprendizagem desses alunos. Assim sendo, este trabalho tem como objetivo, relatar a aplicação do uso de Metodologia Ativa, mas precisamente, ABP que suporta a motivação no processo ensino-aprendizagem.

\section{PROCESSO ENSINO-APRENDIZAGEM E A DESMOTIVAÇÃO}

O processo de ensino/aprendizagem na Educação Básica é diverso, contínuo, formal e informal. Segundo, os estudos atuais, os estudantes aprendem de diversas formas e com variados métodos (MORAN, 2018).

Sendo assim, a aprendizagem, de acordo com Vygotsky (2002, p. 115), “[...] pressupõe uma natureza social específica e um processo através do qual as crianças penetram na vida intelectual daqueles que a cercam". Então, é na relação do discente com o meio em que está inserido, mediado por métodos, que se processa 0 desenvolvimento cognitivo. 


\section{CRIAR EDUCAÇÃO \\ Revista do Programa de Pós-Graduação em Educação - UNESC}
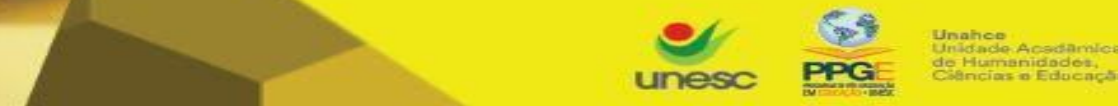

Criar Educação, Criciúma, v. 9, ㄲo 3, ago/dez. 2020 - PPGE - UNESC - ISSN 2317-2452

Desta maneira, no processo de ensino/aprendizagem nem sempre todos os discentes sentem-se motivados. Camargo e Daros (2018) apontam, que enquanto existir o modelo tradicional de ensino, fundamentado unicamente no livro didático e nos exercícios de fixação, que é muito frequente nas escolas do mundo, continuarão sendo gerados discentes e docentes desmotivados para o aprendizado.

De acordo com Bzuneck (2000, p. 9) "a motivação, ou o motivo, é aquilo que move uma pessoa ou que a põe em ação ou a faz mudar de curso". Portanto, a motivação pode ser compreendida como um processo ou aquilo que suscita ou incita uma ação, que sustenta uma atividade progressiva e que direciona a atividade proposta Balancho e Coelho (1996).

Para Parellada e Rufini (2013), um discente desmotivado não tem intenção para realizar as atividades, visto que desvaloriza ou não encontra, naquele momento de ação, subsídios que despertem o seu interesse. Desta forma, diante dos desafios da sociedade contemporânea interpostos à educação, é urgente o desenvolvimento da prática pedagógica por meio de Metodologia Ativa, que possa promover o engajamento e a motivação de estudantes nos trabalhos escolares que oportunize novas aprendizagens (MORAN, 2018).

\section{METODOLOGIA ATIVA}

Na visão de Moran (2018), a Metodologia Ativa pode ser definida por meio da inter-relação entre escola, sociedade, cultura, educação e política. Essa é centrada em atividade com o intuito de propiciar a aprendizagem do aluno por meio criativo e ativo. Visando colaborar com esta ideia, Pereira (2012, p.6) menciona que:

Por Metodologia Ativa entendemos todo o processo de organização da aprendizagem (estratégias didáticas) cuja centralidade do processo esteja, efetivamente, no estudante. Contrariando assim a exclusividade da ação intelectual do professor e a representação do livro didático como fontes exclusivas do saber na sala de aula.

Neste sentido, as Metodologias Ativas surgem como modelo educacional do século $\mathrm{XXI}$, com nova roupagem, propondo minimizar lacunas de interesse e aprendizagem dos discentes (MOREIRA; ANDRADE, 2018). 
Criar Educação, Criciúma, v. 9, № 3, ago/dez. 2020 - PPGE - UNESC - ISSN 2317-2452

Neste cenário, com a Metodologia Ativa, se propõe favorecer à motivação do discente, pois acredita-se que a mesma tem o poder de aguçar a curiosidade, à medida que os discentes se envolvem no processo e na perspectiva do docente (BERBEL, 2011).

Portanto, possibilita ao discente que experimentem situações de aprendizagens significativas em suas vidas, que contrapõem com a atitude passiva, normalmente associada aos métodos tradicionais de ensino Blikstein (2010).

Vale ressaltar que, o uso de metodologias que atraem os discentes, pode ainda propagar práticas tradicionais de ensino, em razão de serem utilizadas para somente ser transmitidas as informações ao estudante, sem sentido de proporcionar uma aprendizagem ativa e significativa (MOREIRA; ANDRADE, 2018).

De acordo com Moreira e Andrade (2018),

\begin{abstract}
Todavia, neste cenário de mudanças, muitos têm considerado que o uso de ferramentas tecnológicas dentro do ambiente escolar seria garantia de uma educação inovadora e criativa. O que nos questionamos é se esse uso basta para a maquiagem nova de um ensino antigo. Nossa preocupação é que o método continue sendo passivo e massificador pela imensa carga de informações transmitidas (agora mediadas pelos aparelhos tecnológicos) pelo docente "ensinador" e detentor da "verdade" ao discente "aprendente" e receptor do saber magistral.
\end{abstract}

Peixoto (2016), afirma que o uso de recursos materiais inovadores de ensino não é suficiente para garantir um ensino motivador e criativo na aprendizagem, porque o mesmo sugere que proponha-se mudança no componente curricular. Considerando que o professor precisa mediar as discussões e necessita manter grupos de discentes concentrados em um problema ou questão específica.

Deste modo, mediante a um ambiente de aprendizagem ativa, o docente como mentor poderá ajudá-los na busca pela autonomia, motivando, questionando e supervisionando, na luta da construção de um estudante ativo e autônomo do seu saber. Nesse processo, o docente passa a ter outras responsabilidades, na construção do conhecimento do discente que passa a fazer pesquisas, reflete e toma decisão, para atingir os objetivos propostos (PEIXOTO, 2016).

Para Moreira e Andrade (2018, p.48),

o docente deve atuar na mediação de discussões; manter grupos de discentes focados em um problema ou tema específico; estimular discentes 
Criar Educação, Criciúma, v. 9, nº 3, ago/dez. 2020 - PPGE - UNESC - ISSN 2317-2452 a se envolverem com as atividades requeridas no processo de busca de solução; despertar o interesse de pensar, observar, raciocinar e entender.

Berbel (2011), apresenta que as Metodologias Ativas possibilitam aprender por meio de experiências, desafios, práticas que ocorrem em várias atividades realizadas no âmbito escolar ou não.

Vale dizer, que algumas metodologias de ensino ativas diferenciadas estão sendo desenvolvidas por docentes, que acreditam ser possível facilitar mudanças significativas em suas práticas pedagógicas (SOUZA; DOURADO, 2015).

Existem algumas metodologias consideradas ativas para ser utilizada no processo ensino-aprendizagem, sendo estas: Aprendizagem Baseada em Problemas, Aprendizagem Baseada em Investigação, Aprendizagem Baseada em Projetos, entre outras Metodologias Ativas são mencionadas no livro "Metodologias Ativas para uma Educação Inovadora”, organizado por Lilian Bacich e José Moran (2018). Mas, para este trabalho, por questões de tempo, contexto de onde foi feita a aplicação e recursos, optou-se pela aplicação da Aprendizagem Baseada em Problemas (ABP). Essa surge como uma estratégia de método inovador em que os discentes trabalham com o objetivo de solucionar um problema real ou simulado inserido em um contexto (MORAN, 2018).

Destaca-se que é um método de aprendizagem centrado no estudante, que se torna um parceiro pesquisador e protagonista de seu aprendizado por meio da pesquisa e resolução de problemas (SOUZA; DOURADO, 2015).

Rocha e Lemos (2014), enfatizam que essa ferramenta está ganhando espaço, devido à necessidade de os discentes desenvolverem inúmeras habilidades para a vida, adquirindo experiências de aprendizagem multifacetadas, em oposição ao método tradicional de ensino. Dessa maneira, esta abordagem apresenta benefícios, porquanto incluem a adaptação aos problemas estudados, tanto no contexto cultural, social e científico. Enfim, o docente e o discente devem adaptar-se às necessidades do trabalho, assim possivelmente será na vida profissional futura de ambos.

Deste modo, é observado em sala de aula um problema que os discentes levantam nas aulas e posteriormente o docente orienta o processo de ensino/aprendizagem, buscando as prováveis soluções (MOREIRA; ANDRADE, 2018). 
Afinal, pode-se observar que "os modelos curriculares da ABP são largamente construtivistas na sua natureza, pois é dada a oportunidade aos alunos de construírem o conhecimento" (CARVALHO, 2009, p.35). Com este método, propõe-se que o discente ao contato com as informações e a produção do conhecimento, passe a selecionar e a utilizar recursos de investigação e técnicas, com mais frequência. Deste modo, o mesmo, poderá ser mais competente na busca de informações. E, os docentes são vistos como facilitadores da solução de problemas (ALBANESE; MITCHEL, 1993; BARELL, 2007; BARRETT; MOORE, 2011).

Assim, a pesquisa realizada por Moreira e Andrade (2018), aponta que estas tendências pedagógicas citadas anteriormente, apresentam o propósito da aprendizagem ser motivada por experiência e aplicação, rompendo com os métodos tradicionais de ensino/aprendizagem, possibilitando o incremento da tecnologia nas aulas.

Uma vez que o uso de metodologias ativas, mais precisamente Aprendizagem Baseada em Problemas é indicada na literatura, passa-se a verificar empiricamente se a mesma suporta a motivação no processo ensino-aprendizagem.

\section{MÉTODO}

$\mathrm{Na}$ elaboração deste trabalho, foi realizado a revisão de literatura de forma exploratória, com ênfase na Metodologia Ativa - ABP - como proposta de ferramenta à promoção e a motivação dos discentes no processo de ensino/aprendizagem.

Para verificar a ferramenta proposta, esse relato de experiência utilizou o método da pesquisa-ação educacional, visto que apresenta uma estratégia para os docentes e pesquisadores, de maneira que ambos possam usar suas pesquisas para melhorar o processo de ensino/aprendizagem (TRIPP, 2005). A pesquisa-ação ocorreu na disciplina de Geografia, em uma escola estadual da região da AMESC. Numa turma da $2^{\text {a }}$ Série do Ensino Médio noturno, composta de 13 educandos, entre 15 e 22 anos, que trabalham em período integral.

A pesquisa ação realizada, nesse relato de experiência, foi desenvolvida em duas etapas, na primeira foi utilizada a metodologia tradicional de ensino e no segundo 
Criar Educação, Criciúma, v. 9, ㄲo 3, ago/dez. 2020 - PPGE - UNESC - ISSN 2317-2452

momento, sendo aplicada a Metodologia Ativa - ABP. Com o intuito de comparar os resultados obtidos.

Na próxima seção será apresentado o relato da pesquisa-ação na referida escola.

\section{RELATO DA PESQUISA-AÇÃO DO USO DE METODOLOGIA ATIVA NO PROCESSO DE ENSINO/APRENDIZAGEM NAS AULAS DE GEOGRAFIA}

$\mathrm{Na}$ primeira etapa, os discentes tiveram a experiência de vivenciar uma metodologia de um ensino tradicional, baseada em aulas expositivas, leitura do conteúdo sobre a "Formação do Território Brasileiro", em fotocópias, com posteriores resoluções de exercícios e para finalizar o conteúdo uma prova com consulta da temática abordada. Corroborando com a prática pedagógica mencionada anteriormente, Moreira e Andrade (2018), enfatizam que os métodos tradicionais de ensino se baseiam em cópias, memorização, repetição e o professor é o detentor de todo o saber.

Nesta etapa, verificou-se que dos treze discentes, nove educandos tiraram notas abaixo da média 6,0 e alguns discentes faltaram e/ou chegaram atrasados nas aulas. Segundo Camargo e Daros (2018), o ensino totalmente transmissivo, centrado somente no conhecimento do docente, é motivo para muitas desmotivações. Nesta perspectiva, eles reclamam da rigidez do tempo, do distanciamento do conteúdo e dos poucos recursos tecnológicos utilizados. Podendo assim ser um dos motivos pela média abaixo do esperado, bem como dos atrasos e ausências.

No segundo momento da pesquisa foi aplicada a estratégia metodológica ABP. Inicialmente, houve a explicação, foi analisado e discutido a relevância do problema para os discentes. Sendo o problema proposto, com base na seguinte indagação: Qual a história da "Casa de Comércio Sasso"? O motivo pelo qual foi escolhida esta pergunta está associada há um critério de acessibilidade, uma vez que a mesma, localiza-se próxima da casa de muitos estudantes da turma e todos conhecem este estabelecimento, que fica localizado na comunidade de Nova Roma, no município de Morro Grande/SC, onde situa-se o objeto de estudo da pesquisaação. 
Ainda quanto à escolha da Casa Sasso, destaca-se que na visão de Zilli (2014) é uma casa de comércio antiga usada pelos tropeiros e pelas pessoas da região e que atualmente se encontra abandonada. A mesma pode contribuir na história da comunidade, podendo despertar o desejo de desenvolver algum projeto com o intuito de preservar e torná-la, um patrimônio material do município.

Outro motivo foi a construção da pavimentação asfáltica, que acabou desmoronando um pedaço da casa de comércio e logo em sala de aula os estudantes começaram a questionar sobre: Qual a história da "Casa de Comércio Sasso"? Neste momento, os questionamentos e o envolvimento da turma foi de suma importância, visto que fomentaram a motivação da pesquisa. Pois, segundo TRIPP (2005), considera que é benéfico incluir os discentes na pesquisa, pois o estudo de uma situação social, pode melhorar sua ação. E tornar a pesquisa mais participativa, democrática e socialmente crítica.

Para tal, eles foram motivados para realizar a pesquisa bibliográfica sobre a história da "Casa de Comércio Sasso", por meio do uso da internet, nos computadores da escola e em seus smartphones. Após a pesquisa, foram realizadas anotações dos principais dados encontrados e socializaram um debate para explanar a pesquisa. Fato que vai ao encontro do que proposto por Tripp (2005), em que a pesquisa-ação tem como característica ser participativa, pois inclui todos os envolvidos e colaborativa no seu jeito de lidar. Em seguida, foi sugerido uma entrevista com a dona da casa de comércio, para confirmar a importância e a realidade do problema da pesquisa. Assim, com essa ferramenta de aprendizagem, os discentes passaram a "aprender a fazer", pois o foco neste processo está no aprendizado, portanto o aprender passa a ser um processo ativo de pesquisa e formação, baseado na curiosidade, no interesse e experiência do discente (ENEMARK; KJAERSDAM, 2018).

No decorrer, das aulas foram realizados questionamentos a ser perguntado à dona da Casa de Comércio Sasso e posteriormente, todos os estudantes, em um período noturno de aula, foram em busca da resolução do problema. Prontamente, a entrevista aconteceu na casa da atual dona do estabelecimento, de 93 anos. Foi um momento único, de inúmeras perguntas, valorização de um bem da comunidade e de muita emoção da dona. Nesta mesma ocasião, ocorreu a visita in loco na casa de comércio, com a colaboração dos familiares. Deste modo, todos os estudantes 
Criar Educação, Criciúma, v. 9, № 3, ago/dez. 2020 - PPGE - UNESC - ISSN 2317-2452

levaram seus smartphones para gravar e tirar fotos do lugar. Corroborando com a temática Enemark e Kjaersdam (2018) apontam que a ABP tem o intuito de aprender a fazer ou aprender na ação, na perspectiva de desenvolver novos conhecimentos.

Logo, em outro período de aula, foi verificado as respostas das perguntas e também foi escutado alguns áudios e gravações que os estudantes realizaram naquele momento, com o auxílio de alguns computadores e smartphones. Em outro momento, ocorreu também a elaboração de um texto, nas aulas de Geografia e de Língua Portuguesa. Com o término do texto, foi editado um vídeo explicativo da problemática estudada, com o uso de seus smartphones e dos computadores da escola. Para Moran (2018) a sala de aula pode ser um lugar excepcional de maker, de buscas de solução, que discentes e docentes instrui-se com situações reais, experiências, problemas, com recursos tecnológicos simples ou sofisticados.

Em seguida, ocorreu a divulgação da pesquisa no evento "Dia da Terra", aberto a toda comunidade escolar. Fato que vai de encontro ao proposto por Enemark e Kjaersdam (2018), que afirmam que os conhecimentos são avaliados por meio de pesquisas e debates em equipes, possibilitando a interação necessária a condução de um ensino inovador. Assim, neste momento de feedback todos os estudantes da turma participaram e mostraram envolvimento no assunto, resultando em notas acima da média, visto que os estudantes sentiram-se parte da pesquisa.

Por fim, com esta pesquisa-ação pode-se verificar que na primeira etapa os resultados baseados em um ensino tradicional procederam em nove estudantes com notas abaixo da média 6,0, numa turma de treze educandos. Além disso, alguns discentes faltaram e chegaram atrasados nas aulas, sem motivação para estudar. Todavia, com a aplicação da Metodologia Ativa - ABP - todos os discentes alcançaram nota superior à média 6,0, em todo o processo avaliativo. Além disto, pode-se observar nas respostas dos questionários aplicados aos discentes sobre 0 uso de Metodologia Ativa - ABP - teve a confirmação que serviu de suporte para analisar os dados da pesquisa. E também, observou-se nos argumentos dos discentes que ressaltaram a importância do uso desta ferramenta para compreender melhor o conteúdo, não tiveram dificuldade na pesquisa, sentiram-se motivados a solucionar o problema e gostaram das atividades pedagógicas aplicadas com o uso dos recursos tecnológicos. Corroborando com a ideia acima (BERBEL, 2011) afirma 
Criar Educação, Criciúma, v. 9, № 3, ago/dez. 2020 - PPGE - UNESC - ISSN 2317-2452

que, com a aplicação da Metodologia Ativa, pode promover na vida dos educandos uma aprendizagem significativa, de maneira a encorajá-los a exercitar a pesquisa, solucionar problemas e a desenvolver dentre outras práticas pedagógicas que favoreçam a motivação.

Portanto, com o uso da Metodologia Ativa - ABP - verificou-se que contribuiu para a motivação dos discentes no processo de aprendizagem, da turma da $2^{\text {a }}$ Série do Ensino Médio noturno. Enfim, essa ferramenta serve de referência para os docentes interessados em promover mudanças em sua prática pedagógica e em desenvolver uma educação mais significativa para seus discentes.

\section{CONSIDERAÇÕES FINAIS}

Com o intuito de motivar os discentes no processo de ensino/aprendizagem, nas aulas de Geografia, foi aplicado o uso de Metodologia Ativa, mais precisamente de $A B P$, em uma turma de Ensino Médio. Pode-se verificar que no primeiro momento com o modelo tradicional de ensino, a maioria dos discentes apresentaram pouco envolvimento na temática e consequentemente, notas baixas. Já com o uso da Metodologia Ativa - ABP - os estudantes mostraram-se motivados nas aulas, resultando assim em notas acima da média. Com base nesta percepção, vislumbrouse que a ferramenta $A B P$ foi eficaz para os docentes durante a pesquisa-ação, uma vez que com o uso da ABP houve a motivação dos estudantes, eles se engajaram nos conteúdos abordados. $\mathrm{E}$ os dados da pesquisa confirmam a sua eficácia no processo de ensino e aprendizagem, do uso da Metodologia Ativa, ABP.

O uso da ABP para o docente mostrou-se efetivo, ela pode aprimorar a prática pedagógica e auxiliar a alcançar o objetivo pedagógico. Ressaltando que, é uma Metodologia Ativa, que colocou o estudante como protagonista no processo de ensino/aprendizagem, por meio da pesquisa-ação contextualizada com o lugar em que os discentes vivem. Para a ciência, esta pesquisa serve de suporte para ser utilizada em outras turmas do Ensino Médio, de diversas disciplinas e unidades escolares. Portanto, a ABP é uma excelente Metodologia Ativa e que pode motivar os estudantes que estão acostumados com um ensino tradicional, muitas vezes, maçante e descontextualizado. 
Criar Educação, Criciúma, v. 9, № 3, ago/dez. 2020 - PPGE - UNESC - ISSN 2317-2452

Como trabalhos futuros, recomenda-se, utilizar outros recursos tecnológicos para fazer uma maquete em corte e laser, para aumentar o conhecimento acerca da temática abordada. Sugere-se, também, verificar se a ABP poderá colaborar na redução da taxa de evasão escolar dos discentes em que foram executadas as Metodologias Ativas de aprendizagem.

\section{REFERÊNCIAS}

ALBANESE, M. A.; MITCHELL, S. Problem-Based Learning: A review of literature on its outcomesand implementation issues. Academic Medicine, 68, p. 52-81, 1993.

BALANCHO, M. J. S.; COELHO, F. M. Motivar os alunos, criatividade na relação pedagógica: conceitos e práticas. 2. ed. Porto, Portugal: Texto, 1996.

BARELL, J. Problem-Based Learning. An Inquiry Approach. Thousand Oaks: Corwin Press. 2007.

BARRETT, T.; MOORE, S. New Approaches to Problem-Based Learning. Revitalising your practice in higher education. New York: Routledge, 2011.

BERBEL, N. A. N. A. As metodologias ativas e a promoção da autonomia de estudantes. Seminário: Ciências Sociais e Humanas, Londrina, v. 32, n. 1, p. 25-40, jan./jun. 2011.2 Disponível em: < http://www.proiac.uff.br/sites/default/files/documentos/berbel_2011. pdf>. Acesso em: 17 maio 2018.

BLIKSTEIN, P. O mito do mau aluno e porque o Brasil pode ser o líder mundial de uma revolução educacional. 2010. Disponível em: http://www.blikstein.com/paulo/documents/books/BliksteinBrasil_pode_ser_lider_mun dial_em_educacao.pdf Acesso em: 05 maio 2019.

BZUNECK, J. A. As crenças de auto-eficácia dos professores. In: F.F. Sisto, G. de Oliveira, \& L. D. T. Fini (Orgs.). Leituras de psicologia para formação de professores. Petrópolis, Rio de Janeiro: Vozes, 2000.

CAMARGO, Fausto; DAROS Thuinie. A sala de aula inovadora: estratégias pedagógicas para fomentar o aprendizado ativo. Porto Alegre: Penso, 2018.

CARVALHO, C. J. A. O Ensino e a Aprendizagem das Ciências Naturais através da Aprendizagem Baseada na Resolução de Problemas: um estudo com alunos de 9ํ ano, centrado no tema Sistema Digestivo. Dissertação de Mestrado, Universidade do Minho, 2009.

ENEMARK, Stig; KJAERSDAM, Finn. A ABP na teoria e na prática: a experiência de aalborg na inovação do projeto no ensino universitário. In: ARAÚJO, Ulisses F.; 
SASTRE, Genoveva (org.). Aprendizagem Baseada em Problemas no Ensino Superior. 4. ed. São Paulo: Summus, 2018. Cap. 1. p. 17-42.

FREIRE, Paulo. Pedagogia do Oprimido. Rio de Janeiro: Paz e Terra, 1970.

KENSKI, Vani Moreira. Tecnologia e ensino presencial e a distância. $9^{a}$ ed. Campinas, SP: Papirus, 2012.

MORAN, José. Metodologias ativas para uma aprendizagem profunda. In: MORAN, José; BACICH, Lilian (Org.). Metodologias ativas para uma educação inovadora: uma abordagem teórico-prática. Porto Alegre: Penso, 2018.

MORAN, José. O EAD no Brasil: cenário atual e caminhos viáveis de mudança. In: Educação a distância: pontos e contrapontos. Local: Summus Editorial, 2011, p 4588. Disponível em: http://www2.eca.usp.br/moran/wpcontent/uploads/2013/12/cenario. Acesso em: 09 de abril 2019.

MOREIRA, Marco Aurélio. ANDRADE, Maria Celeste de Moura. Metodologias ativas no Ensino Superior: Possibilidade ou "faz de conta"? Evidência, Araxá, v.14, n.15, p.43-57, 2018.

PARELLADA, Ibelmar Lluesma; RUFINI, Sueli Édi. O uso do computador como estratégia educacional: relações com a motivação e aprendizado de alunos d o ensino fundamental. Psicol. Reflex. Crit., Porto Alegre, v. 26, n. 4, Dec.2013. Disponível em: http://www.scielo.br/scielo.php?pid=S0102 79722013000400015\&script=sci abstract\&tlng=es. Acesso em: 18 maio 2019.

PEIXOTO, A. G. $O$ uso de metodologias ativas como ferramenta de potencialização da aprendizagem de diagramas de caso de uso. Periódico $\begin{array}{llllll}\text { científico outras palavras. } & \text { V. } & 12, & \text { v.2, } & 2016 .\end{array}$ Disponívelem:http://revista.faculdadeprojecao.edu.br/index.php/Projecao5/article/vie w/718/604. Acesso em: 27 abril 2019.

PEREIRA, Rodrigo. Método Ativo: Técnicas de Problematização da Realidade aplicada à Educação Básica e ao Ensino Superior. In: VI Colóquio internacional. Educação e Contemporaneidade. São Cristóvão, SE. 20 a 22 setembro de 2012.

PRENSKY, Marc. Não me atrapalhe, mãe - Eu estou aprendendo! São Paulo: Phorte, 2010. $320 \mathrm{p}$.

PRENSKY, Marc. Nativos digitais, imigrantes digitais. Tradução de Roberta de Moraes Jesus de Souza, 2001.

ROCHA, H. M.; LEMOS, W. M. Metodologias Ativas: do que estamos falando? Base conceitual e relato de pesquisa em andamento. IX Simpósio Pedagógico e 


\section{CRIAR EDUCAÇÃO}

Revista do Programa de Pós-Graduação em Educação - UNESC

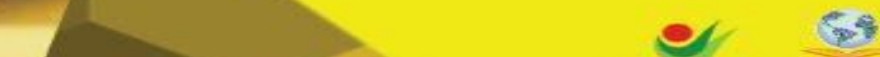

unesc PPG
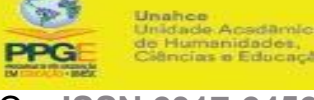

Criar Educação, Criciúma, v. 9, ํㅜㄱ, ago/dez. 2020 - PPGE - UNESC - ISSN 2317-2452

Pesquisas em Comunicação. SIMPED 2014. Disponível em: https://www.aedb.br/wpcontent/uploads/2015/05/41321569.pdf Acesso em: 29 abril 2019.

S. C. SOUZA, L. DOURADO. Aprendizagem Baseada em Problemas (ABP) Um Método de Aprendizagem Inovador para o Ensino Educativo. Instituto Federal de Educação, Ciência e Tecnologia do Rio Grande de Norte - IFRN Universidade do Minho (Portugal). Disponível em: file://C:/Users/User/Downloads/2880-10049-1PB.pdf Acesso: 05 maio 2019.

TRIPP, David. Pesquisa-ação: uma Introdução Metodológica. Educação e Pesquisa, São Paulo, v31, n3, p. 443-466, set/dez. 2005. Tradução: Lólio Lourenço de Oliveira.

VIGOTSKI, L. S. A formação social da mente. 6. ed. São Paulo: Martins Fontes, 2002.

ZILLI, Edson. Caminhos das Tropas no Extremo Sul Catarinense: Memória e Patrimônio. Universidade do Extremo sul Catarinense - UNESC. Curso de História. Criciúma, 2014. Disponível em: https://docplayer.com.br/72842817-Universidade-doextremo-sul-catarinense-unesc-curso-de-historia-edson-zilli-caminhos-das-tropas-noextremo-sul-catarinense-memoria-e-patrimonio.html. Acesso em: 10 maio 2019.

Recebido em agosto de 2020

Aceito em outubro de 2020 